\title{
Semiempirical Methodology for Estimating the Service Life of Concrete Deck Panels Strengthened with Fiber-Reinforced Polymer
}

\author{
Eon-Kyoung Kim, ${ }^{1}$ Hongseob Oh, ${ }^{1}$ and Jongsung Sim ${ }^{2}$ \\ ${ }^{1}$ Department of Civil Engineering, Gyeongnam National University of Science and Technology, 150 Chilam-dong, Jinju, \\ Gyeongnam 660-758, Republic of Korea \\ ${ }^{2}$ Department of Civil and Environmental Engineering, Hanyang University, 1271 Sa1-dong, Ansan-si, \\ Gyeonggi-do 425-791, Republic of Korea
}

Correspondence should be addressed to Hongseob Oh; opera69@chol.com

Received 25 November 2013; Revised 26 February 2014; Accepted 26 February 2014; Published 26 March 2014

Academic Editor: Ting-Hua Yi

Copyright (C) 2014 Eon-Kyoung Kim et al. This is an open access article distributed under the Creative Commons Attribution License, which permits unrestricted use, distribution, and reproduction in any medium, provided the original work is properly cited.

Deterioration of concrete bridge decks affects their durability, safety, and function. It is therefore necessary to conduct structural rehabilitation of damaged concrete decks by strengthening them with fiber-reinforced polymer. Of the recent studies on the strengthened structures, most have focused on static behavior; only a few studies have investigated fatigue behavior. Accurate analysis of fatigue in concrete deck performance requires a more realistic simulated moving load. This study developed a theoretical live-load model to reflect the effect of moving vehicle loads, based on a statistical approach to the measurement of real traffic loads over various time periods in Korea. It assessed the fatigue life and strengthening effect of bridge decks strengthened with either carbon fiber sheets or grid carbon fiber polymer plastic using probabilistic and reliability analyses. It used extrapolations and simulations to derive maximum load effects for time periods ranging from 1 day to 75 years. Limited fatigue tests were conducted and probabilistic and reliability analyses were carried out on the strengthened concrete bridge deck specimens to predict the extended fatigue life. Analysis results indicated that strengthened concrete decks provide sufficient resistance against increasing truck loads during the service life of a bridge.

\section{Introduction}

Upgrading existing concrete structures has been an important issue over the last 30 years. Many studies have focused on developing new technologies to strengthen and retrofit deteriorated structures [1-5]. Within this field, techniques have been developed based on fiber-reinforced polymer (FRP) composites, leading to new and promising developments in civil engineering. In particular, external bonded reinforcement (EBR) using FRP can resist flexural and shear stress; it is a valuable strengthening technique and its use has been well established in many design specifications and references $[6,7]$.

Many researchers have investigated structural performance, such as the ultimate limit and serviceability limit of strengthened material, but few have focused on the service life cycle or durability of the strengthened structure. Strengthening of a concrete structure is mainly intended to improve load-carrying capacity or serviceability. Concrete gradually fails due to fatigue loads, but under service loading states rather than ultimate loading states [10-13]. It is important to clarify how reinforced structures deteriorate and to identify the causes of structural failure, but these issues are sometimes neglected when engineering reinforced structures.

Improving load-carrying capacity and serviceability are undoubtedly important design factors, but extended service life is also important. If the strengthening method used to reinforce a structure ensures the required performance, does it also ensure improved structural performance over its lifecycle? It is important to confirm the long-term performance 
of a reinforced structure in addition to its load-carrying capacity and serviceability [14]. In reinforced concrete (RC) strengthened with externally bonded FRPs, fatigue failure will be initiated by failure of the reinforcing steel and followed by debonding of FRP [8]. Fatigue failure of reinforcing steel can be avoided by limiting FRP stress levels for fatigue loading, but a preferred design technique to prevent fatigue debonding failure has not yet been established. Concrete fatigue performance can be verified either using empirical methods based on test results or analytical methods based on fracture mechanics $[8,15-20]$.

Many assessments of the fatigue performance of strengthened concrete have been limited to laboratories, where tests are conducted under pulsating loading conditions. In the case of bridge deck panels, one main cause of deterioration is deck fatigue failure caused by excessive repeated heavy traffic loads. Continuous static and fatigue tests have verified the failure mechanisms for bridge decks strengthened with fiber-reinforced polymers (FRPs), and simplified flexural and punching shear design procedures and semiempirical fatigue life cycle assessment techniques have been proposed based on the cumulated damage theory $[14,17,21]$. It is difficult to estimate the extended service life for a rehabilitated bridge deck subjected to real moving traffic loads, because to date no practical design methodology for strengthened decks has been developed [16]. Therefore, it is important to develop a model to simulate fatigue loads for both fatigue analysis and fatigue design of bridge decks.

This study developed a semiempirical methodology for fatigue analysis, using a live-load model derived from probabilistic analysis of real traffic data in South Korea and previously obtained fatigue test results. The proposed live traffic model was then tested based on real Korean traffic conditions. Probabilistic approaches and reliability analyses based on restricted test results for the strengthened concrete bridge decks were also applied to verify the strengthening effect and to predict the extended fatigue life. This information is especially important because investigations of bridge deck fatigue performance conducted under laboratory or real bridge deck conditions provide limited data and invariably involve large uncertainties and extensive variations in results.

\section{Live-Load Model}

2.1. Truck Axle Loads. To predict the fatigue life of a bridge, the fatigue analysis should apply the axle loads that pass over the bridge. Land load data can be used to simulate fatigue conditions, including traffic jams, over long periods, but these data are rare and generally not used for fatigue analysis of a bridge structure $[22,23]$. This study developed a liveload model by measuring the crossing frequency and heavyvehicle lane load on the Banpo Bridge in Seoul, Korea. As shown in Figure 1, the Banpo Bridge is located in the middle of Seoul and consists of two separate bridge systems. The upper bridge, used for this analysis, was constructed in 1982, and the lower Jamsu Bridge, which was submerged during a flood, was built from steel plates and RC slabs in 1976. The traffic data used in this study were based on the assumption

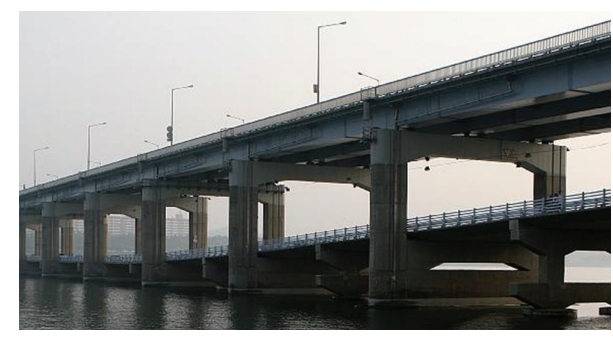

Figure 1: Banpo Bridge consists of steel box girder and concrete deck.

that one load cycle equals one heavy vehicle crossing the bridge.

The Banpo Bridge is classified as a Class 2 bridge by the Korean Highway Bridge Design Specification DB-18 [21]. Korea has three classes of standard truck loading: DB24, DB18, and DB13.5. The load for DB24 is similar to that of HS15, which is classified in standard specifications for highway bridges by AASHTO [24]. Figure 2 shows the standard trucks used in Korea, and Table 1 summarizes the detailed specifications.

Yoon [8] classified the six representative vehicles used in Korea as T2, TT3, ST4, ST5, ST6, and FT5, as shown in Figure 3. For the live-load model used in this study, TT3 and ST5 trucks were used for heavy traffic modeling because they generally provide more traffic volume than other truck types, based on average traffic volume. Both normal and overloaded trucks were considered when applying a fatigue load to the bridge deck. To determine normal and overloaded truck loads, a traffic frequency analysis was conducted for both TT3 and ST5 truck types. On the basis of these results, the TT3 truck type was selected as the standard axle load based on traffic frequency $(N=2,137$ normal, $N=330$ overloaded) and the rear axle loads were determined ( $84 \mathrm{kN}$ normal, $133.9 \mathrm{kN}$ overloaded). Table 2 lists the rear axle loads used in this study, for both normal and overloaded states.

Figure 4 shows the distribution of axle weight for a TT3 truck. The fatigue life of reinforced concrete deck slabs is mainly related to the upper tail parts of the axle weight distribution. The impact load factor was calculated using $i=20 /(50+L)$ based on the Korean Highway Design Specification [25] because no factor was available for fatigue conditions related to reinforced concrete bridge decks.

This study used the average daily truck traffic (ADTT) on the Banpo Bridge provided by the Korean Ministry of Construction and Transportation [9] (see Table 3) to simulate the actual traffic frequency. The coefficient of variation was 0.85 based on ASSHTO [24] for a one-way three-lane road, but given the critical condition of fatigue load, this model applied a 1.0 coefficient of variation, making the ADTT 4,400.

2.2. Live-Load Model. It has been studied that the moving and cyclic load can affect reinforced concrete bridge deck more 4 to 7 times than that of static cyclic load. In present, however, only static cyclic load has been adopted for fatigue analysis of the bridge deck. Therefore, the live-load model for fatigue analysis of the bridge deck was developed by using Type I 

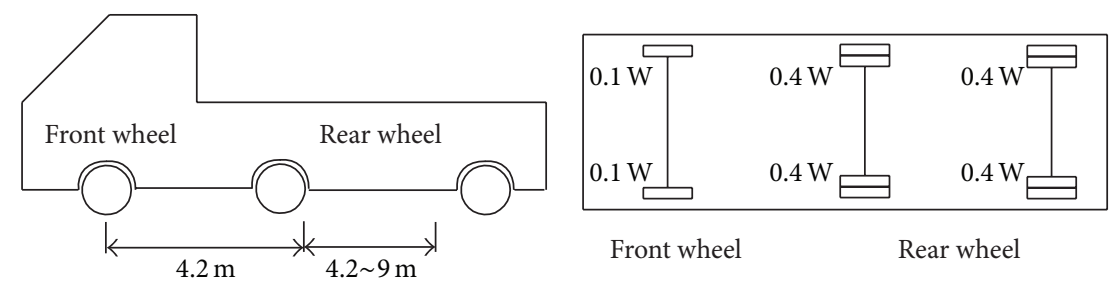

Figure 2: The scheme of standard design truck in Korea.

TABLE 1: Detailed specification of standard truck loads in Korea.

\begin{tabular}{lcccc}
\hline Bridge grade & Load grade & Total truck load $1.8 \mathrm{~W}(\mathrm{kN})$ & Front axle load 0.1 W $(\mathrm{kN})$ & Rear axle load 0.4 W $(\mathrm{kN})$ \\
\hline Class 1 & DB-24 & 432 & 24 & 96 \\
Class 2 & DB-18 & 324 & 18 & 72 \\
Class 3 & DB-13.5 & 243 & 13.5 & 54 \\
\hline
\end{tabular}

TABle 2: Actual truck axle loads [9].

\begin{tabular}{ll}
\hline Truck & Axle loads \\
\hline
\end{tabular}

(a) Axle loads in the normal state

$58.4 \mathrm{kN}$

TT3 (N: 2,137)

$84.1 \mathrm{kN}$

$84.0 \mathrm{kN}$

$49.4 \mathrm{kN}$

$65.2 \mathrm{kN}$

ST5 ( $N: 948)$

$65.7 \mathrm{kN}$

$82.2 \mathrm{kN}$

$68.1 \mathrm{kN}$

(b) Axle loads in an overloaded state

$58.4 \mathrm{kN}$

TT3 $(N: 330)$

$133.9 \mathrm{kN}$

$84.0 \mathrm{kN}$

$49.4 \mathrm{kN}$

$65.2 \mathrm{kN}$

ST5 (N: 97)

$112.4 \mathrm{kN}$

$82.2 \mathrm{kN}$

$68.1 \mathrm{kN}$

extreme function, based on the well-established assumptions by Collins and Nowak [26] and Nowak et al. [27], adopting actually measured lane load from Table 2 . Using the classification set out by Gumbull [28], the cumulative distribution function (CDF) of Type I asymptotic form for the largest value distribution is

$$
F_{Y_{n}}\left(y_{n}\right)=\exp \left[-e^{-\alpha_{n}\left(y_{n}-u_{n}\right)}\right]
$$

where $u_{n}$ and $a_{n}$ are the location and scale parameters, respectively, defined as follows:

$u_{n}=$ characteristic largest value of the initial variate $X$,

$a_{n}=$ inverse measure of the $X_{n}$ dispersion.
The corresponding probability of density function (PDF) is

$$
\begin{array}{r}
f_{Y_{n}}\left(y_{n}\right)=\alpha_{n} e^{-\alpha_{n}\left(y_{n}-u_{n}\right)} \exp \left[-e^{-\alpha_{n}\left(y_{n}-u_{n}\right)}\right], \\
-\infty<y_{n}<\infty .
\end{array}
$$

Parameters $u_{n}$ and $a_{n}$ represent the relationship between the average and standard deviation and can be determined using

$$
u_{n}=\mu_{Y_{n}}-\frac{0.5772}{\alpha_{n}}, \quad \alpha_{n}=\frac{1}{\sqrt{6}}\left(\frac{\pi}{\sigma_{Y_{n}}}\right) .
$$

For the smallest value from an initial variate $X$ with an "exponential tail," the corresponding Type I asymptotic form for the CDF is

$$
\begin{aligned}
& F_{Y_{l}}=1-\exp \left[-e^{-\alpha_{l}\left(y_{l}-u_{l}\right)}\right] \\
& f_{Y_{l}}=\alpha_{l} e^{-\alpha_{l}\left(y_{l}-u_{l}\right)} \exp \left[-e^{-\alpha_{l}\left(y_{l}-u_{l}\right)}\right], \quad-\infty<y_{l}<\infty,
\end{aligned}
$$

where the parameters are

$$
\begin{aligned}
& u_{l}=\text { characteristic smallest value of the initial variate } \\
& X, \\
& a_{l}=\text { inverse measure of } X_{1} \text { dispersion. }
\end{aligned}
$$

Parameters $u_{l}$ and $a_{l}$ also represent a relationship between the average and standard deviation and can be determined using

$$
u_{l}=\mu_{Y_{l}}+\frac{0.5772}{\alpha_{l}}, \quad \alpha_{l}=\frac{1}{\sqrt{6}}\left(\frac{\pi}{\sigma_{Y_{l}}}\right) .
$$

Therefore, the maximum axle load formed as a standard distribution can be determined by generating pseudorandom numbers for the axle load. This study assumed that the values of the coefficient of variation and average nominal ratio for an adopted axle load to an extreme function were 0.25 and 1.24, respectively, based on Collins and Nowak [26].

Figures 5 and 6 show the live-load model results for axle loads based on the extreme function of a bridge and a service life of 75 years required by the Design Specifications for 


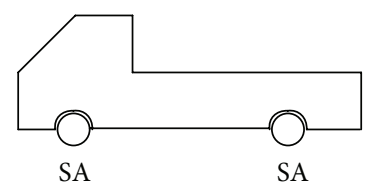

(a) Type T2

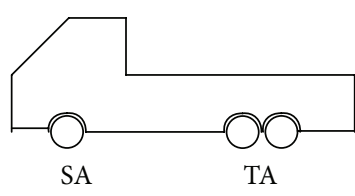

(b) Type TT3

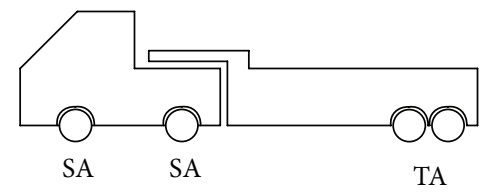

(c) Type ST4
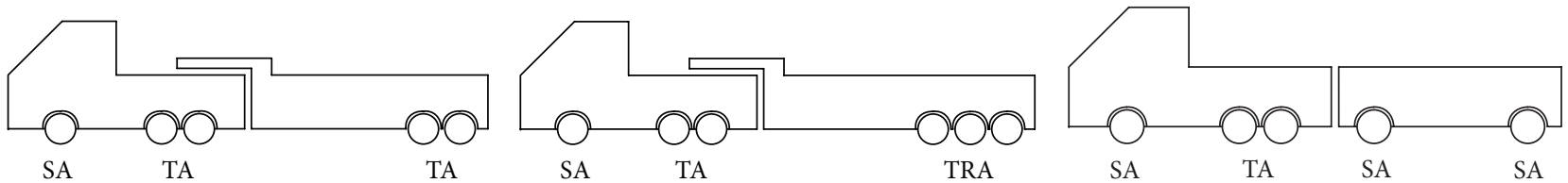

(d) Type ST5

(e) Type ST6

(f) Type FT5

FIGURE 3: Various truck types considered for live-load model [8].
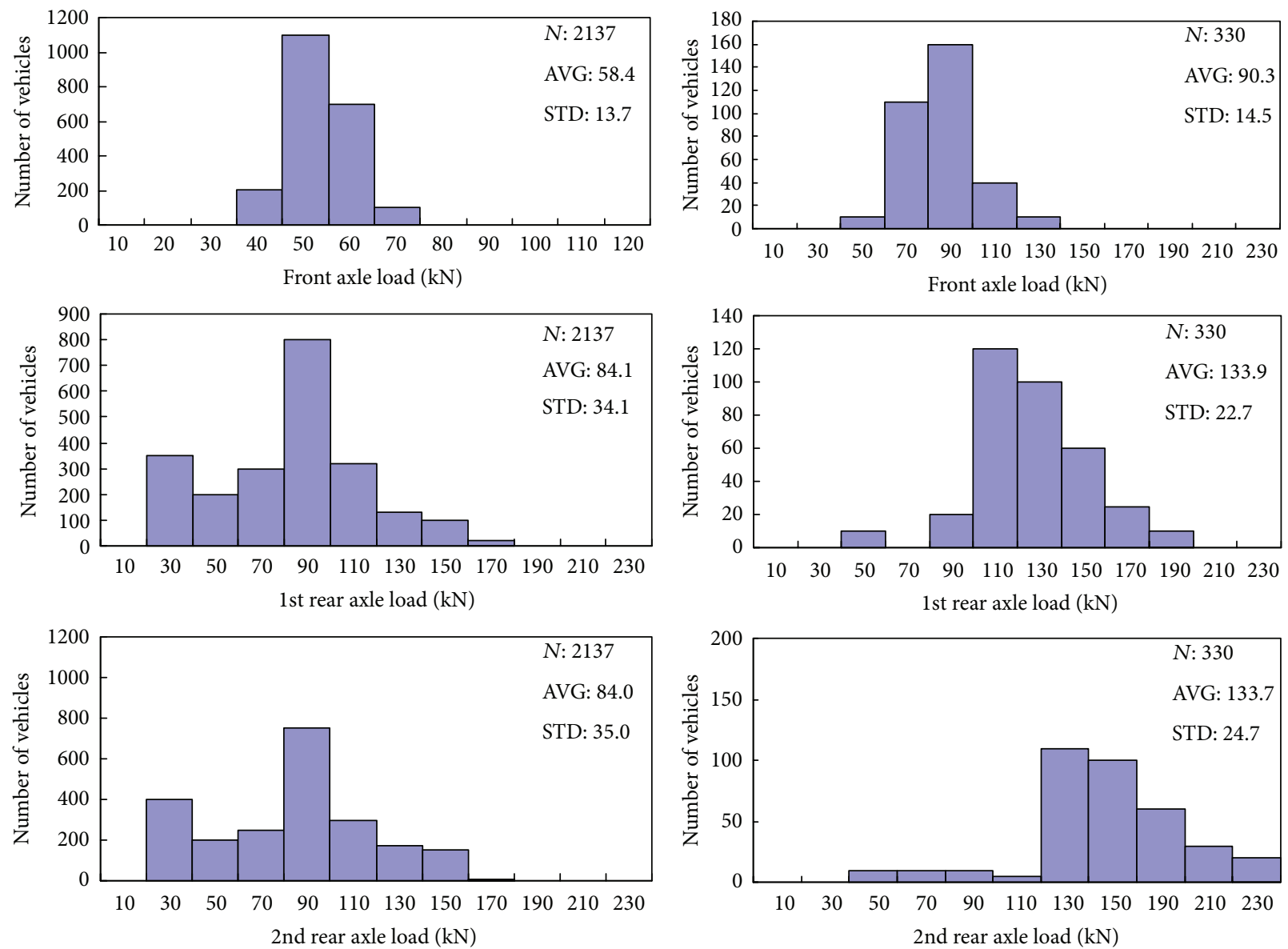

(a) Axle loads in the normal state

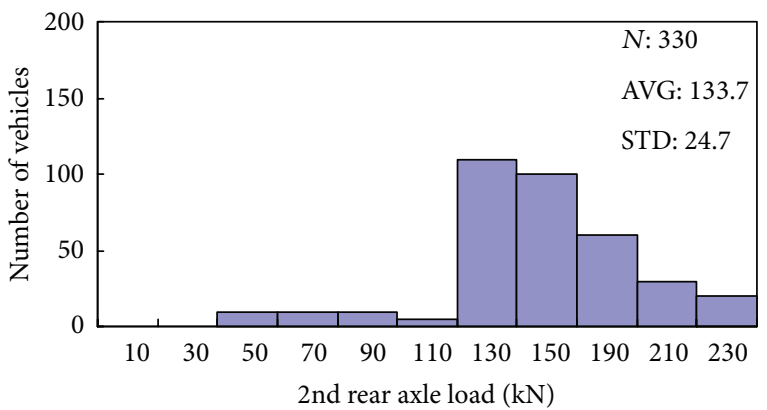

(b) Axle loads in an overloaded state

Figure 4: Probability frequency of a TT3 truck.

TABLE 3: Average daily truck traffic (ADTT) of Banpo Bridge.

\begin{tabular}{|c|c|c|c|c|}
\hline & \multirow{2}{*}{ Passenger vehicle } & \multirow{2}{*}{ Bus } & \multicolumn{2}{|c|}{ Truck } \\
\hline & & & Normal state truck & Overloaded state truck \\
\hline Six-lane road & 121,954 & 17,510 & 23,405 & 3,200 \\
\hline ADTT & 20,326 & 2,918 & \multicolumn{2}{|c|}{$4,434(4,400)$} \\
\hline
\end{tabular}




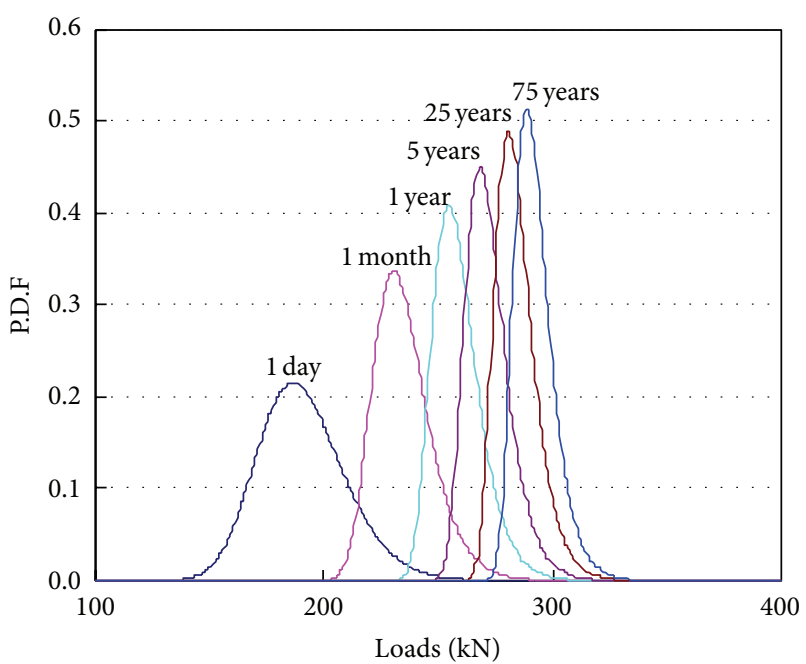

(a) Probability density function

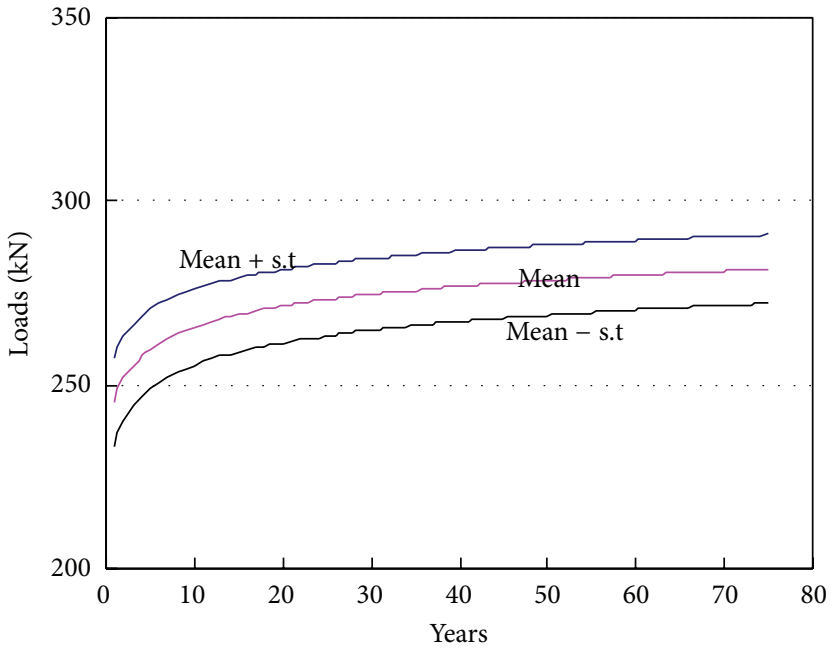

(b) Cumulative distribution function

FIGURE 5: Live-load model (normal state tandem load: $84.0 \mathrm{kN}$ ).

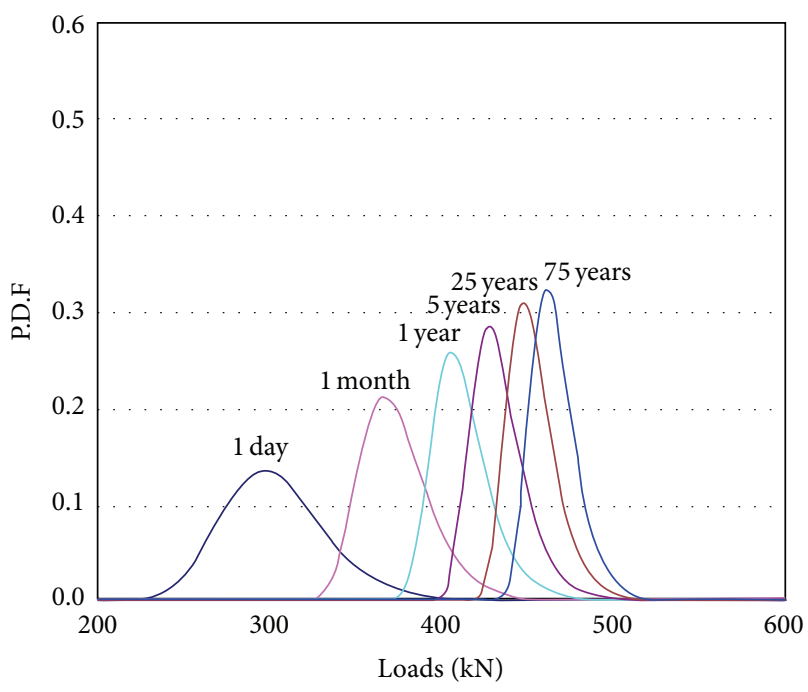

(a) Probability density function

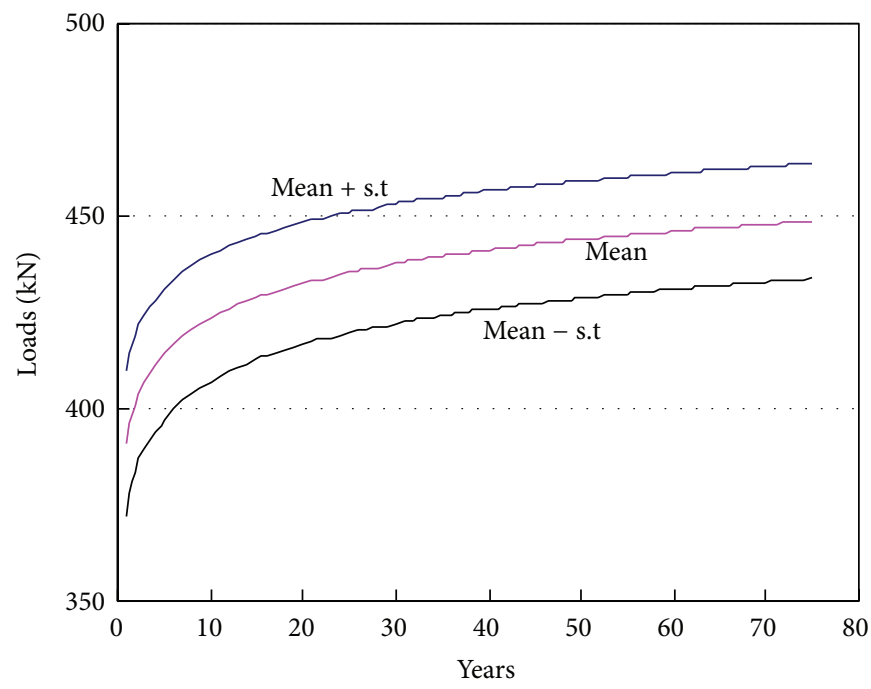

(b) Cumulative distribution function

Figure 6: Live-load model (overloaded state tandem load: $133.9 \mathrm{kN}$ ).

Highway Bridges in Korea [21]. Figures 5(a) and 6(a) indicate the axle load effects for normal state design truck loads and overloaded state truck loads, respectively, as a probability density function (PDF) at 1 day, 1 and 6 months, and 1, 5, 25, 50, and 75 years. Figures 5(b) and 6(b) show the cumulative distribution function (CDF); this function produced a shape similar to that of Nowak's live-load model.

The probabilistic analysis revealed that the load effect of a normal state, in which the tandem load was only $84.0 \mathrm{kN}$, increased to $170.0 \mathrm{kN}$ at 1 day and $281.5 \mathrm{kN}$ at 75 years, respectively, as shown in Figure 5. For an overloaded truck with an axle load of $133.9 \mathrm{kN}$, the loading effect was 298.0 (1 day) and $461.0 \mathrm{kN}$ (75 years), respectively. Therefore, the live-load effect should be incorporated when estimating the fatigue life of a bridge deck.

\section{Structural Performance of Strengthened Deck Panels}

3.1. Experimental Program and Summary of Results. Some previous researchers have found that the fatigue life of a deck panel under a moving load is four to seven times less than when it is under a pulsating load and that this has a large effect on real bridge decks $[10,18]$. Only a few studies have investigated the fatigue test results of ordinary decks 

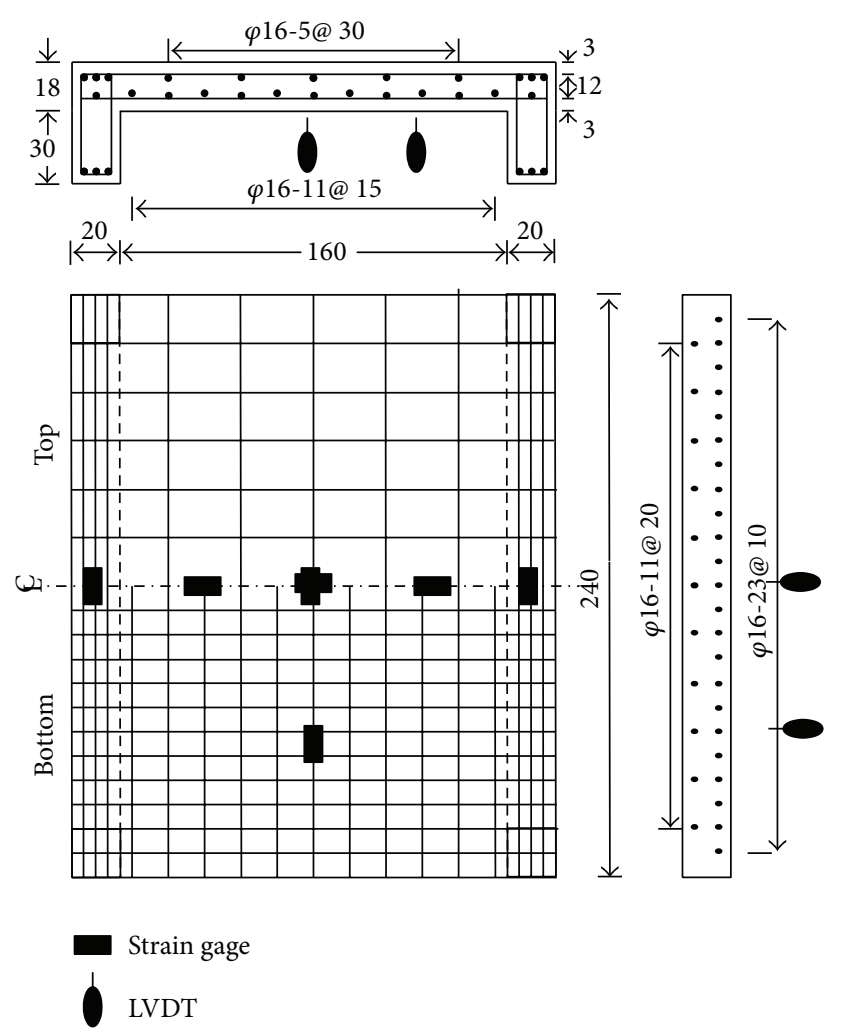

Figure 7: Specimen details (unit: $\mathrm{cm}$ ).

and strengthened decks under a moving load, so the fatigue analyses of bridge decks in this study are based on the author's previous fatigue testing on ordinary and strengthened decks under pulsating loads.

To assess the static and fatigue behavior of strengthened deck panels, a total of 12 deck specimens were prepared, and carbon fiber sheet (CFS) and grid typed carbon fiberreinforced polymer (GCFRP) were used as strengthening materials. During the experimental test program, a prototype $160 \times 240$-cm $(63 \times 94.5$-in $)$ deck panel was used to simulate a real bridge deck supported by two girders, as described in previous studies $[14,17]$. In order to simulate the structural behavior of real bridge deck, 3-dimensional nonlinear finite element analyses were carried out before and after the physical experiments. The concrete slab was modeled with 8-node solid elements, reinforcing bars with beam elements. The dimension of FE model and sectional properties of deck panel were varied and analyzed to simulate the similar behavior with real deck. The selected deck section for test is depicted in Figure 7 and is simulated in the secondary bridge deck used in Korea, in which design traffic loads are similar to HS20 truck. As a result, the dimensions selected for the deck were similar to the size of actual decks used in Korea.

Deck panels were fabricated using ordinary Portland cement, natural sand, and crushed coarse aggregate with a maximum size of $25 \mathrm{~mm}$ ( $0.984 \mathrm{in})$. The compressive strength of the concrete was $22.5 \mathrm{MPa}$ (3262.5 psi) after curing for 28 days. Deformed bars with a diameter of $15.9 \mathrm{~mm}$ (0.626 in) and average yield strength of $300 \mathrm{MPa}(43500 \mathrm{psi})$ were used in the deck panels and beams. Table 4 summarizes the properties of the materials used during testing.

The slab thickness was $18 \mathrm{~cm}$ (7.09 in), identical to that of secondary bridge decks in Korea. The tensile rebar spacing was $10 \mathrm{~cm}$ in the transverse direction, and the reinforcement spacing was $15 \mathrm{~cm}$ (5.91 in) in the longitudinal direction. Figures 7 and 8 show details of the specimens and strengthening methods. A cyclic loading of $2 \mathrm{~Hz}$ was applied to the center of the deck panel, and the loading area was $25 \times 50 \mathrm{~cm}$, similar to the tire contact area. Linear variable differential transformers (LVDTs) and electric strain gages were installed to determine the deflection and strain of rebar and strengthening materials during testing.

In Table 5, CON indicates an unstrengthened reference deck specimen, and CFS and GCFRP indicate deck panels strengthened with CFS and GCFRP, respectively. The stress level of each specimen (with the exception of CON-40, which was designed to verify structural response in a service state) was designed to assess the endurance limit of deck specimens and compare the structural response with that of deck specimens strengthened with other materials and undergoing similar loads. "Stress level" refers to the ratio of the load applied in fatigue testing to the ultimate strength, which was acquired from previous research [14]. CFS material was bonded to the prototype deck panel in an upside-down position. Each fiber sheet was attached to the epoxy-coated surface by pressing it into the epoxy. The GCFRP material was first fixed to the concrete surface in an upside-down position using $2.5 \mathrm{~cm}$ (0.98 in) anchor bolts spaced every $50 \mathrm{~cm}$ (19.7 in). Subsequently, the manufacturer's recommended repair mortar was overlain on the concrete surface.

3.2. Summary of Fatigue Test Results. Failure patterns of deck panels subjected to less stress appeared to be dominated by initial microcracking at the midpoint, but the failure patterns of deck panels subjected to more stress were similar to those of decks subjected to monotonic loads. Therefore, when designing real concrete decks, it is also important to consider the stress level to control cracking either by strengthening the pattern or the amount.

The failure surface of panels subjected to more stress had a greater angle than that of panels subjected to less stress. In the case of decks strengthened with FRP sheets, complete debonding could not occur because the FRP sheets distributed tensile stresses and kept flexural cracks relatively small. Major cracks on the sheet branched out into numerous minor cracks, because the FRP reinforcement arrested the cracks. As shown in Table 5, all specimens strengthened with FRP sheets failed eventually after repeated cyclic loads due to shear mode punching after transverse sheet ruptures. In the case of decks strengthened with GCFRP, cracking was considerably denser than in decks strengthened with sheettype material, but the crack spacing was similar to that of FRP. No spalling of overlayed mortar was observed before deck panels failed, but the mortar separated from the concrete during testing. Deck panels strengthened with GCFRP failed due to shear punching and the detachment of perfectly overlain mortar. Panel GCFRP 60 failed abruptly due to 


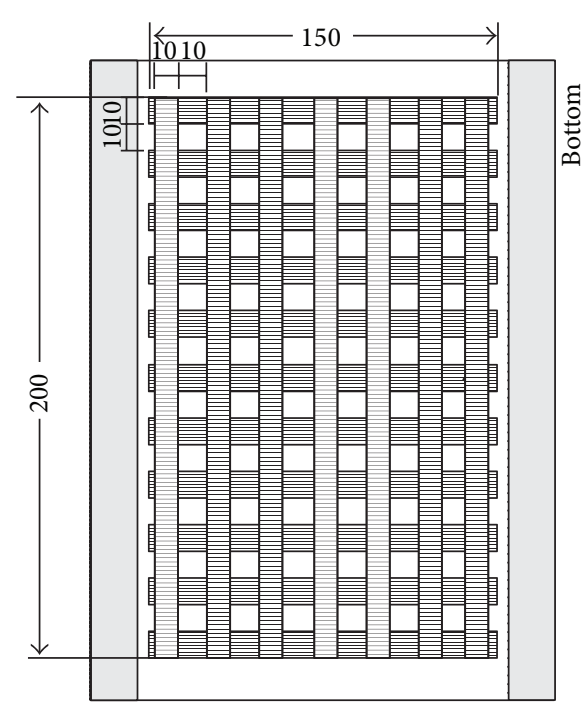

(a) CFS

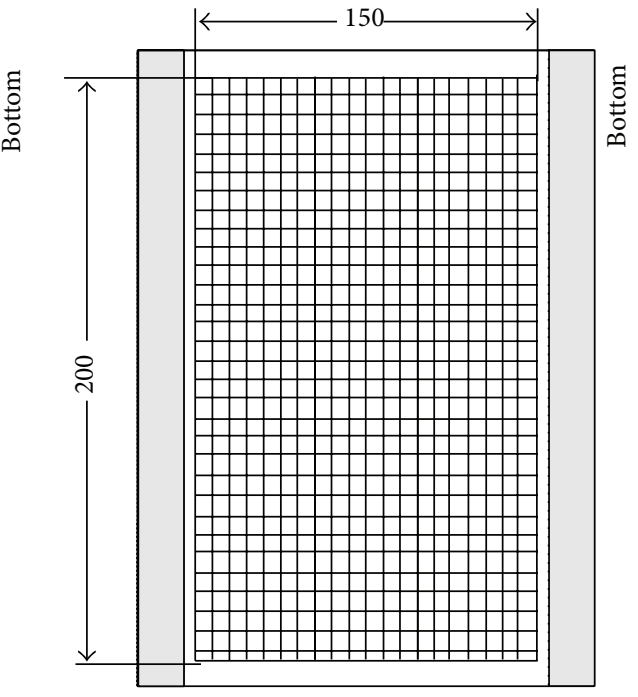

(b) GCFRP

FIGURE 8: Strengthening methods.

TABLE 4: Physical properties of the materials.

\begin{tabular}{|c|c|c|c|c|c|}
\hline & $\begin{array}{c}\text { Thickness or } \\
\text { diameter }\end{array}$ & $\begin{array}{l}\text { Yield strength } \\
(\mathrm{MPa})\end{array}$ & $\begin{array}{l}\text { Ultimate strength } \\
(\mathrm{MPa})\end{array}$ & $\begin{array}{c}\text { Elastic modulus } \\
(\mathrm{MPa})\end{array}$ & Ultimate strain \\
\hline Concrete & & - & 22.5 & $0.232 \times 10^{5}$ & - \\
\hline Rebar & $13 \mathrm{~mm}$ & 300 & 400 & $1.96 \times 10^{5}$ & - \\
\hline Epoxy & & - & 88.3 & $0.07 \times 10^{5}$ & - \\
\hline Carbon fiber sheet & $0.11 \mathrm{~mm}$ & - & 3,500 & $2.31 \times 10^{5}$ & 0.015 \\
\hline $\begin{array}{l}\text { GCFRP (grid typed } \\
\text { carbon fiber-reinforced) }\end{array}$ & $4.0 \mathrm{~mm}$ & - & 1,170 & $1.00 \times 10^{5}$ & 0.0117 \\
\hline Mortar for GCFRP & & & 27.0 & $0.14 \times 10^{5}$ & - \\
\hline
\end{tabular}

concrete girder collapse prior to deck slab failure. In Figure 9, load-displacement relationships of deck specimens subjected to static load and $70 \%$ cyclic loading of ultimate strength are depicted. Residual displacement of deck panel caused by cyclic loading is linearly increased in initial cyclic loading state and then, as the cumulated fatigue damage reached failure state, increment of residual displacement is abruptly amplified.

Fatigue damage in strengthened and traditional RC samples consisting of concrete, rebar, and strengthening material cannot be defined using these strain concepts and a numerical approach based on nonlinear fracture mechanics. The residual life cycle of deteriorated RC bridge deck panels is repeatedly subjected to an unknown number of traffic loads and external aggressive effects, so it is difficult to evaluate them using the local strain concepts applied by other researchers. Here, fatigue damage to deck panels before and after strengthening was evaluated based on the loaddisplacement relationship represented by an overall structural response. Fatigue damage will be defined here as $\delta / \delta_{\max }$, where $\delta$ is the cumulative displacement at any load cycle and $\delta_{\max }$ is the maximum displacement prior to failure. As pointed out earlier, $\delta_{\max }$ for cyclic loading was slightly higher than the maximum displacement observed during static testing, for both unstrengthened and strengthened panels, provided they were subjected to the same strengthening method.

Figure 10 presents the ratios of cumulative displacement to deflection at ultimate static loads for each specimen. Initial displacement of CFS60 and GCFRP60 (data not shown) appeared to be similar to that of CON70, which received almost the same load size as strengthened specimens with a stress level of $60 \%$. As the number of loading cycle increased, cumulative displacement of CON60 increased more than did that of strengthened panels. Other strengthened specimens had a stress level of $80 \%$; these are not shown in the figure, but they appeared to exhibit greater structural stiffness than unstrengthened deck panels. The structural stiffness of the GCFRP series was smaller than that of other strengthened deck panels, but these deck panels failed due to ductile properties, with the exception of the GCFRP60 panel. 


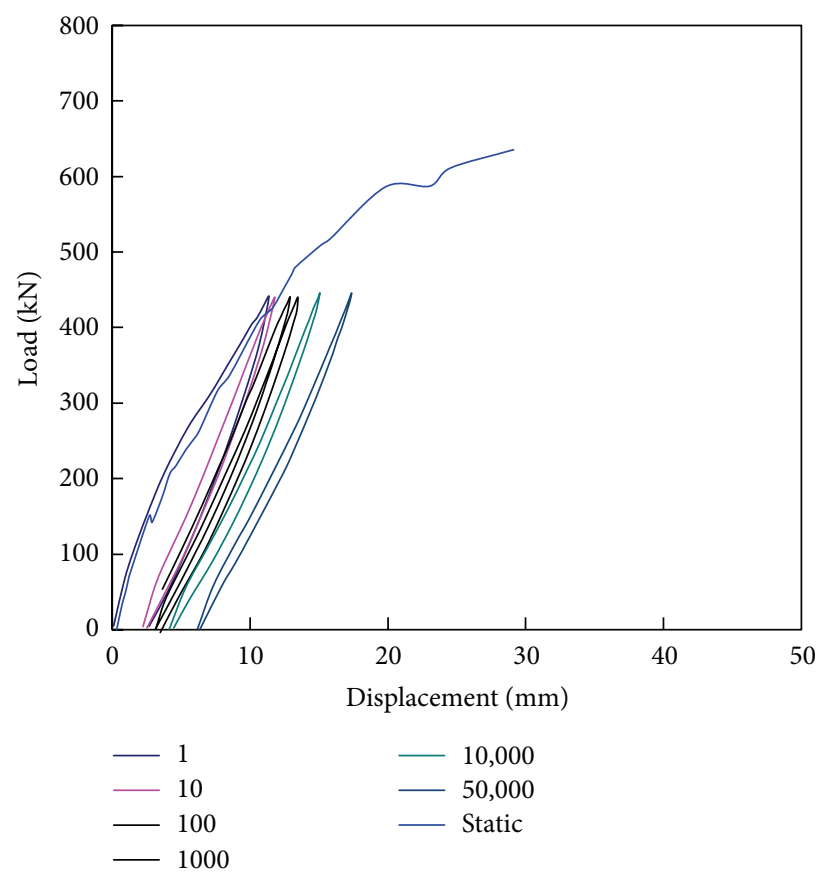

(a) CON70

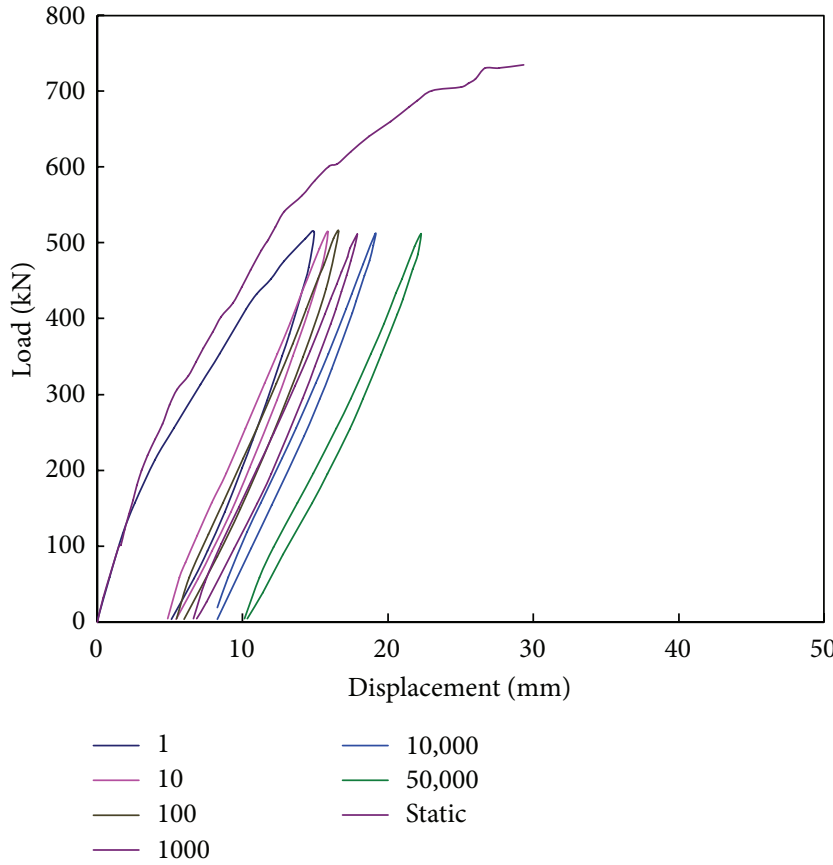

(b) CFS70

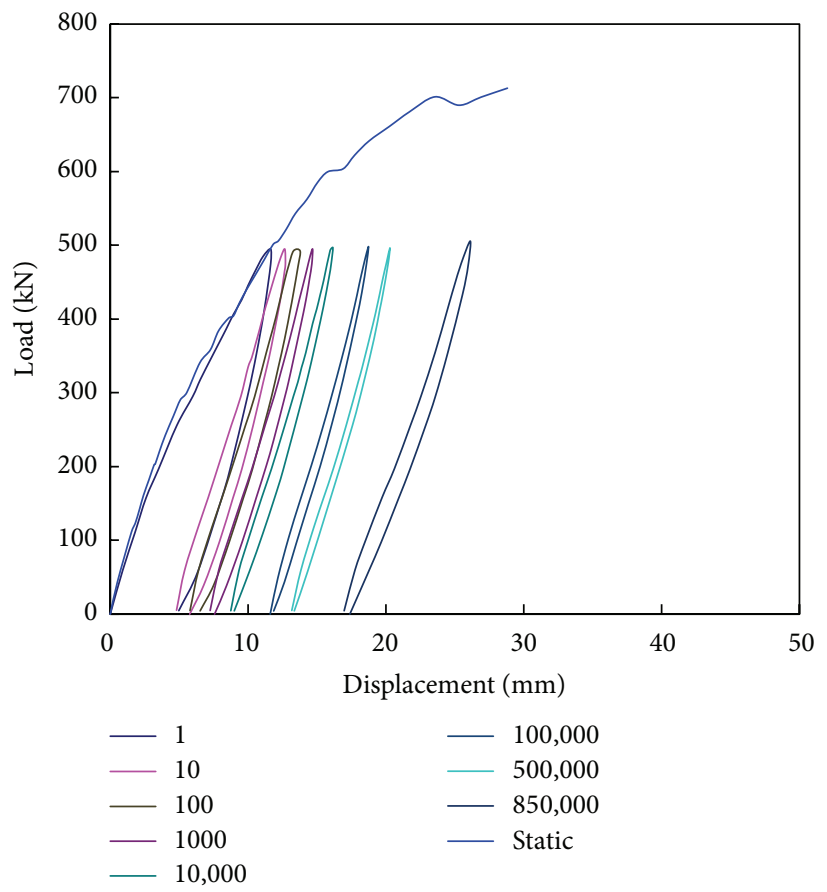

(c) CGFRP70

FigurE 9: Load-displacement relationship of deck specimens under 70\% stress level.

\section{Fatigue Analysis Based on the Probabilistic Approach}

This study conducted probabilistic fatigue analyses to evaluate the fatigue characteristics of bridge deck specimens strengthened with FRP. This probabilistic analysis applied the Weibull distribution to evaluate the probability of failure and hazard function for the specimens. Oh [15] found that the Weibull distribution function may be compatible with the fatigue behaviour. The Weibull distribution is based on physically more convincing arguments. The applicability of the Weibull distribution to concrete fatigue is, therefore, investigated in the following section [29]. The Weibull distribution has been widely applied in fatigue analysis because it 
TABLE 5: Stress level and test results.

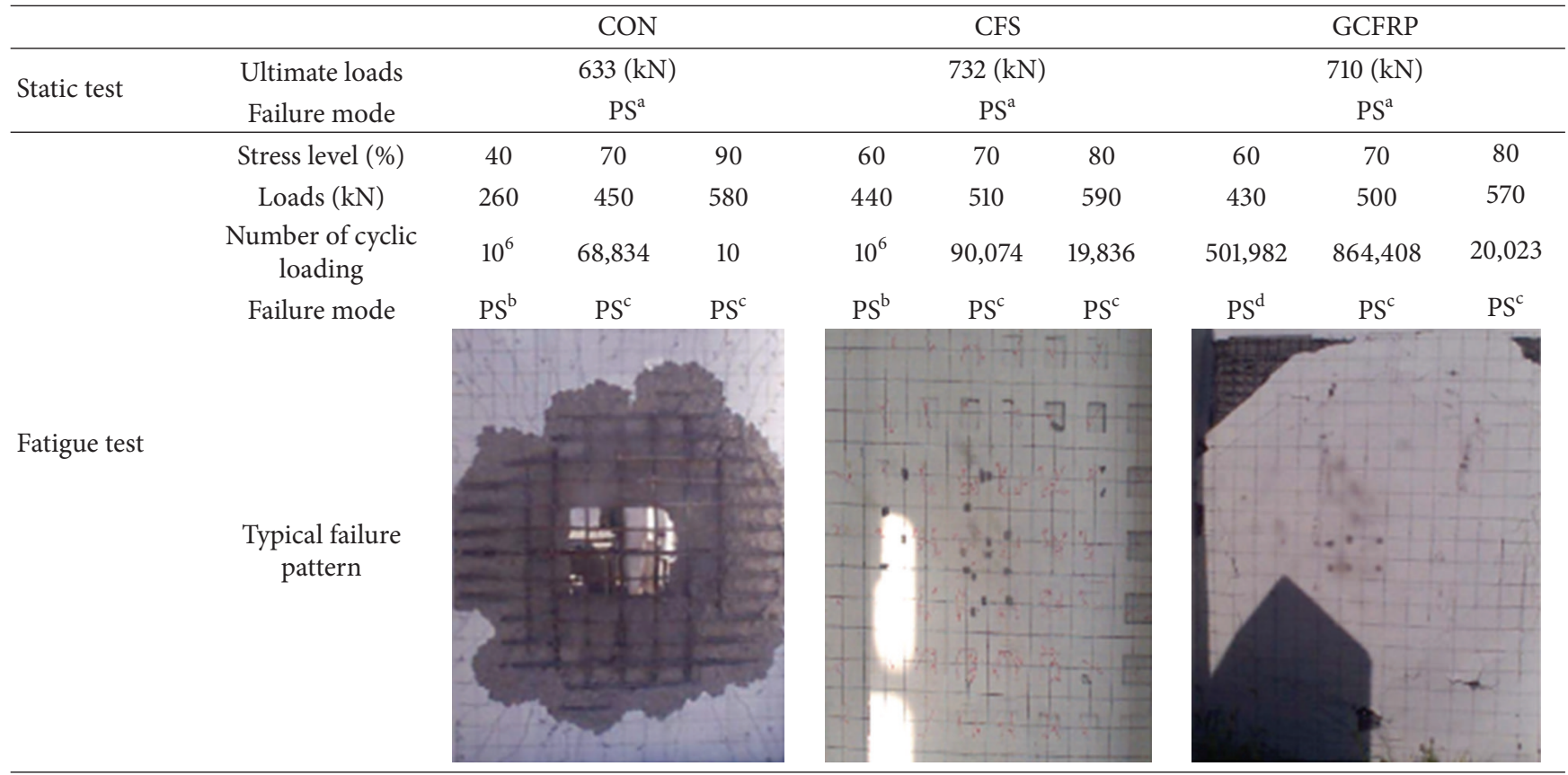

Note: $\mathrm{PS}^{\mathrm{a}}$ : punching shear failure after yielding of rebar, $\mathrm{PS}^{\mathrm{b}}$ : punching shear failure due to static loading, $\mathrm{PS}^{\mathrm{c}}$ : fatigue punching shear, and $\mathrm{PS}^{\mathrm{d}}$ : fatigue punching shear failure after girder collapse.

can explain the physical phenomena of fatigue response well $[15,16]$.

The probability of density function (PDF) and cumulative distribution function (CDF) obtained using the Weibull distribution are defined by

$$
\begin{gathered}
\text { PDF: } f_{N}(n)=\frac{k}{u-n_{0}}\left(\frac{n-n_{0}}{u-n_{0}}\right)^{k-1} \exp \left[-\left(\frac{n-n_{0}}{u-n_{0}}\right)^{k}\right], \\
n \geq n_{0}, \\
\text { CDF: } F_{N}(n)=1-\exp \left[-\left(\frac{n-n_{0}}{u-n_{0}}\right)^{k}\right], \quad n \geq n_{0},
\end{gathered}
$$

where $u$ is a scaling parameter or the characteristic life at stress level $S, k$ is a shape parameter, $n$ is the fatigue life, and $n_{0}$ is the minimum fatigue life. Previous studies have reported that $n_{0}=0$ is an appropriate value for predicting the fatigue response $[15,26,27,29-31]$. This study obtained parameters $k$ and $u$ from the $S-N$ relationship in fatigue testing.

The hazard function, which represents the fatigue characteristics of a given concrete specimen, increases harmonically with accumulated fatigue damage [15]. The hazard function indicates the probability that the specimen will collapse between time $(0, t)$ and $(t, t+d t)$ and can be expressed as

$$
h(t)=\lim _{\Delta t \rightarrow 0} \frac{L(t)-L(t+\Delta t)}{\Delta t L(t)}=\frac{1}{L(t)}\left(-\frac{d}{d t} L(t)\right)=\frac{f(t)}{L(t)},
$$

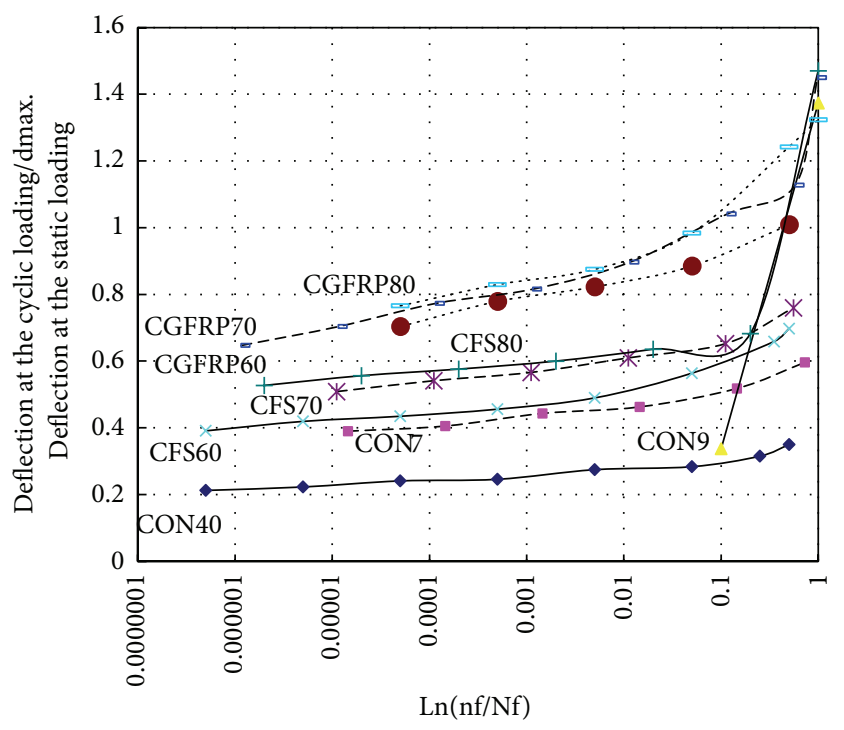

FIGURE 10: Ratio of cumulated deflection to maximum deflection at ultimate strength at cyclic loading.

where $f(t)$ is the probability of density function. Therefore, the hazard function for the Weibull distribution can be obtained by substituting (6) into (7):

$$
h_{N}(n)=k\left(\frac{n-n_{0}}{u-n_{0}}\right)^{k-1}, \quad n \geq n_{0} .
$$




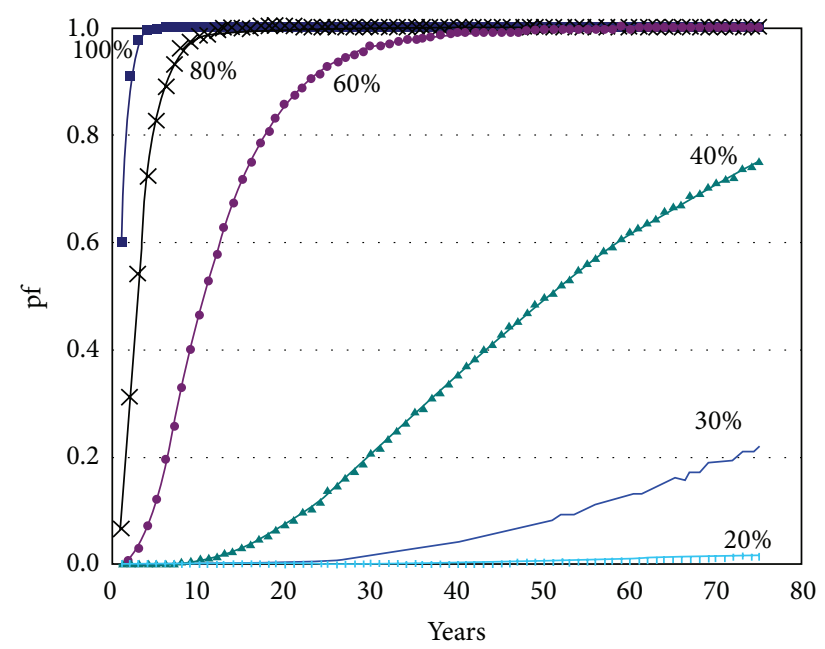

(a) $\mathrm{CON}$

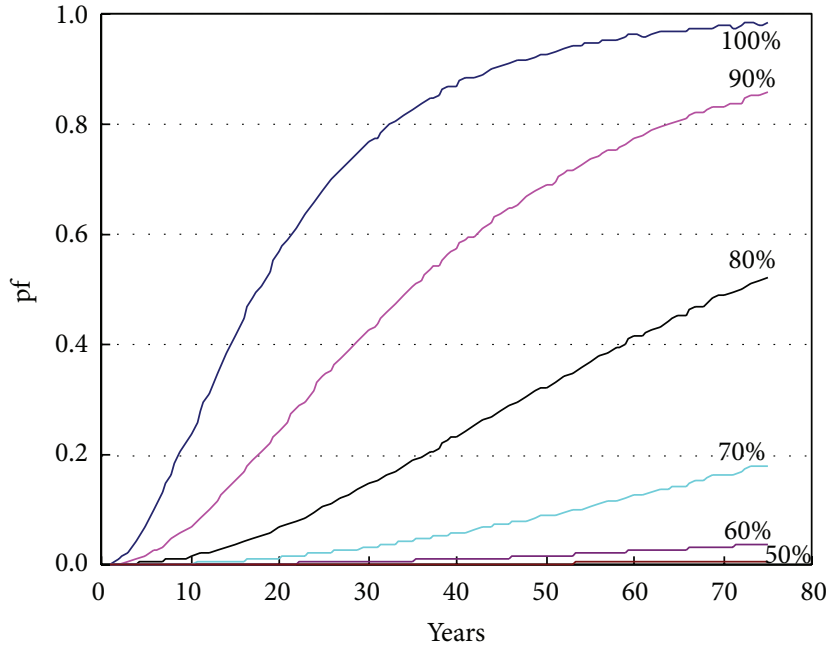

(b) CFS

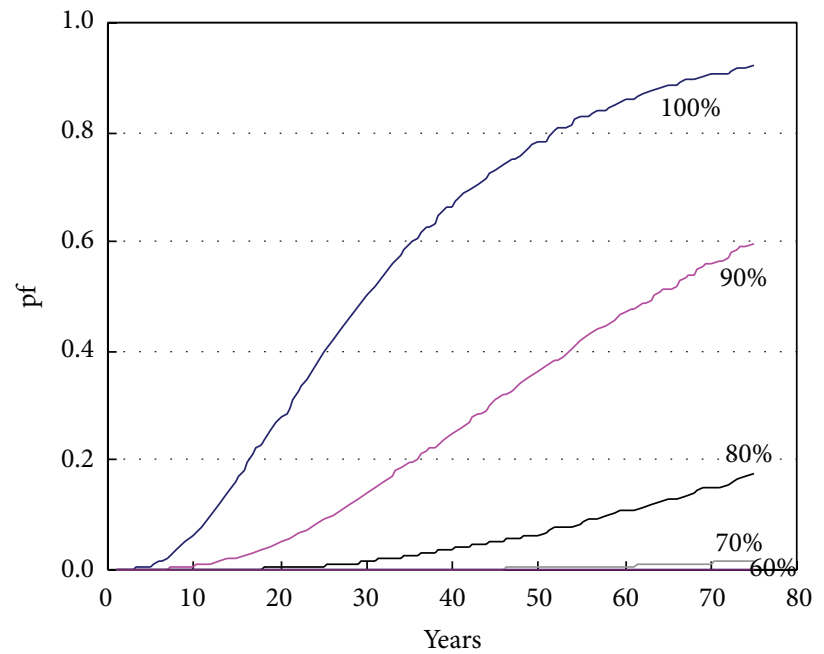

(c) CGFRP

FIGURE 11: Failure probability of test specimens.

Based on test results, the stress level $(S)$ and fatigue life $\left(N_{f}\right)$ were $N_{f} \times S^{A}=B$, and parameters $k$ and $u$ were calculated using [16]

$$
k^{2}=\frac{\pi^{2}}{6 s^{2}}, \quad \ln u=\frac{0.5772}{k}+\ln \left(B \times S^{-A}\right),
$$

where $S$ is the standard deviation of $\ln \left(N_{f}\right), k$ is a Weibull distribution shape parameter, and $A$ and $B$ are experimental constants. $S, k, A$, and $B$ were calculated based on test results and are listed in Table 6.

The $S-N$ relationships can be acquired from the fatigue test results using regression analysis:

CON specimen: $N_{f} S^{30.279}=1.795$,

CFS specimen: $N_{f} S^{33.254}=1.962$,

CGFRP specimen: $N_{f} S^{38.948}=1.392$.
TABLE 6: A probabilistic coefficient of specimens.

\begin{tabular}{cccc}
\hline & CON & CFS & CGGFP \\
\hline$K$ & 2.827 & 1.325 & 2.702 \\
$A$ & 30.279 & 33.254 & 38.948 \\
$B$ & 1.795 & 1.962 & 1.392 \\
$S$ & 0.454 & 0.968 & 0.475 \\
\hline
\end{tabular}

Sample moments in the expected fatigue life may also be used to estimate the distribution parameters. Moments in Weibull distribution can be expressed as follows:

$$
E[N]=u \Gamma\left(1+\frac{1}{k}\right)=B \times S^{-A} \exp \left[\frac{0.5772}{k}\right] \Gamma\left(1+\frac{1}{k}\right),
$$

where $E[]$ indicates an expected value and $\Gamma()$ represents the gamma function. 


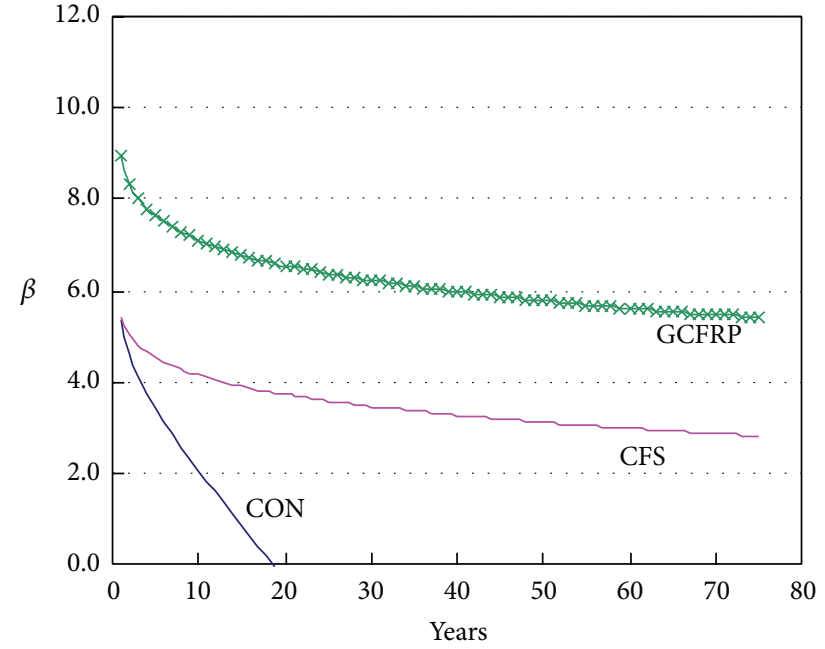

(a) $50 \%$

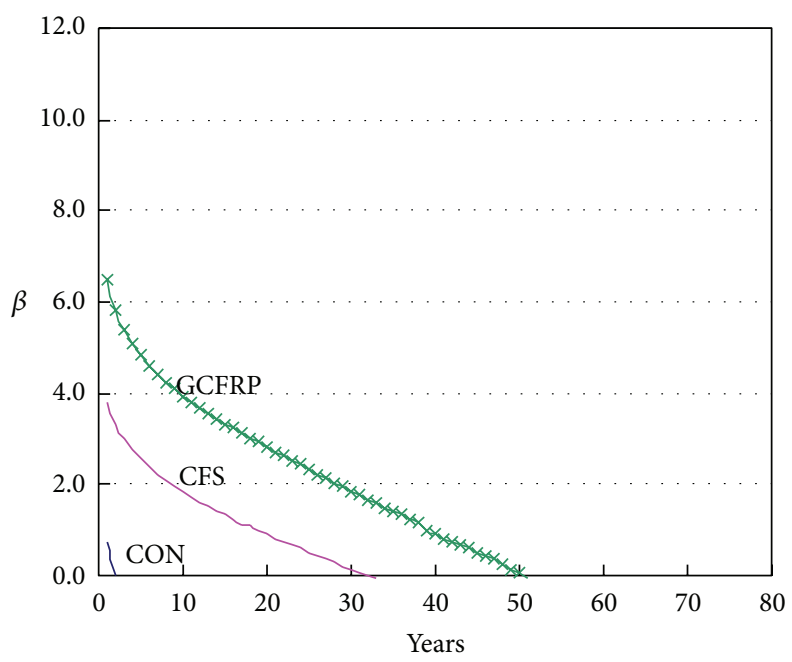

(b) $90 \%$

FIGURE 12: Reliability indexes of the rate of overloaded trucks to the total trucks.

TABLE 7: Axle load for the mixed rate of overloaded trucks $(\mathrm{kN})$.

\begin{tabular}{|c|c|c|c|c|c|c|c|c|c|c|c|}
\hline Mixed rate of overloaded trucks & $0 \%$ & $10 \%$ & $20 \%$ & $30 \%$ & $40 \%$ & $50 \%$ & $60 \%$ & $70 \%$ & $80 \%$ & $90 \%$ & $100 \%$ \\
\hline Axle loads $(\mathrm{kN})$ & 84.0 & 89.0 & 94.0 & 99.0 & 104.0 & 109.0 & 113.9 & 118.9 & 123.9 & 128.9 & 133.9 \\
\hline
\end{tabular}

TABLE 8: Random variables for reliability analysis.

\begin{tabular}{lccc}
\hline Variables & Mean & COV & Distribution \\
\hline Traffic & 4,400 & 0.20 & Normal \\
Axle load & $1.24 \times$ axle load & 0.25 & Lognormal \\
\hline
\end{tabular}

The appropriate selection of the design fatigue life $\left(N_{D}\right)$ should result in a small probability of fatigue failure. Once the distribution function has been determined, an appropriate design fatigue life can be selected subsequent to an acceptable $P\left[N<N_{D}\right]=1-p_{f}$, where $p_{f}$ is the probability of failure. Given that $P\left[N>N_{D}\right]=p_{f}$, the design fatigue life corresponding to a permissible probability $p_{f}$ can be determined using the following relationship:

$$
\begin{aligned}
p_{f} & =1-\exp \left(-\left(\frac{n-n_{0}}{u-n_{0}}\right)^{k}\right), \\
N_{D} & =u\left[\ln \left(\frac{1}{1-p_{f}}\right)\right]^{1 / k} .
\end{aligned}
$$

If both the load effect $(R)$ and resistance $(Q)$ are continuous random variables, the safety of a structure can be expressed as $Z=R-Q[15,26,27]$. If $Z \leq 0$, it represents a failure condition. Therefore, the probability of failure is

$$
\begin{aligned}
p_{f} & =P[R<Q]=P[Z=R-Q<0]=\Phi_{z}(-\beta) \\
\beta & =\frac{\mu_{R}-\mu_{Q}}{\sqrt{\sigma_{R}^{2}+\sigma_{Q}^{2}}},
\end{aligned}
$$

where the reliability index $\beta$ can be calculated using geometry $[26,27] ; \beta$ is the inverse of the coefficient of variation of function $Z$ when $R$ and $Q$ are uncorrelated.

Table 7 lists the mixing rate of overloaded trucks on the bridge deck of Class 2 bridge; (12) can be used to calculate the probability of failure of the deck panel. Table 8 shows the coefficients of variation and distribution based on the Monte Carlo simulation method.

Figure 11 shows the probability of failure for each test variable. CON bridge deck panels had less than a $1 \%$ probability of failure at a 75 -year service life and a $20 \%$ mixing rate of overloaded trucks. However, the results indicated that, if the mixing rate exceeded $70 \%$, CON specimens would fail in 10 years. CFS-strengthened deck panels had less than a $4 \%$ probability of failure at a 75 -year service life and a $60 \%$ mixing rate of overloaded trucks. However, the results for mixing rates greater than $70 \%$ indicated that the probability of failure would increase gradually to almost $100 \%$.

CGFRP-strengthened bridge decks had a $20 \%$ probability of failure at a 75-year service life and an $80 \%$ mixing rate of overloaded trucks; when approaching a failure condition, these decks also had a greater margin of probability of failure than did bridges strengthened with CFS. This probability analysis demonstrated that increased truck loads caused increased rates of damage to bridge decks strengthened with CGFRP, more than for bride decks strengthened with CFS when bridge decks approached failure conditions. CFS and CGFRP specimens had failure probabilities of $98 \%$ and $92 \%$, respectively, indicating that both CFS and CGFRP strengthening can provide sufficient safety margins for a 75year service life. 
Figure 12 shows the reliability index for the mixing rate of overloaded trucks to total trucks for each test specimen. Figure 12 shows how a 50\% mixing rate would affect bridge decks: in this case, the CON specimen failed after about an 18-year service life. The reliability of the CFS specimen approached the safety margin $(\beta=3)$, indicating that this rate of increase in overloaded trucks could be considered the specimen's strengthening limit. Under conditions of a $90 \%$ mixing rate, the reliability indexes fell rapidly: CON, CFS, and CGFRP bridge decks all had service lives of less than 50 years. The results of this analysis indicate that CGFRP-strengthened bridge decks are more reliable than CFS-strengthened bridge decks.

\section{Conclusions}

This study proposed another approach to fatigue design for strengthened structures. The test results and considered variables were limited to the proposed fatigue design technique, so more research will be required for more reliable strengthening of deteriorated concrete structures. The bridge deck reliability index evaluation indicated that both CFS and CGFRP strengthening methods could strengthen bridge decks with increased rates of overloaded trucks. Bridge decks strengthened with CFS or CGFRP extended bridge deck fatigue life by 1.2-1.5 times compared to a nonstrengthened bridge deck. The CGFRP strengthening method resulted in a better reliability index than did the CFS strengthening method with regard to both strengthening and extended fatigue lives. Therefore, CGFRP is a more effective strengthening method than CFS for concrete bridge decks.

\section{Conflict of Interests}

The authors declare that there is no conflict of interests regarding the publication of this paper.

\section{Acknowledgments}

This work was supported by research Grants of Korea Institute of Marine Science \& Technology Promotion (PJT200493) and National Research Foundation of Korea (NRF-2010-0024085).

\section{References}

[1] R. N. Swamy, R. Jones, and J. W. Bloxham, "Structural behavior of reinforced concrete beams strengthened by epoxy-bonded steel plates," The Structural Engineer, vol. 65, no. 2, pp. 59-68, 1987.

[2] H. Saadatmanesh and M. R. Ehsani, "RC beams strengthened with GFRP plates. I. Experimental study," Journal of the Structural Engineering, vol. 117, no. 11, pp. 3417-3433, 1991.

[3] J. G. Teng, S. Y. Cao, and L. Lam, "Behaviour of GFRPstrengthened RC cantilever slabs," Construction and Building Materials, vol. 15, no. 7, pp. 339-349, 2001.

[4] B. Zhang, R. Masmoudi, and B. Benmokrane, "Behaviour of one-way concrete slabs reinforced with CFRP grid reinforcements," Construction and Building Materials, vol. 18, no. 8, pp. 625-635, 2004.
[5] I. Liu, D. J. Oehlers, R. Seracino, and G. Ju, "Moment redistribution parametric study of CFRP, GFRP and steel surface plated RC beams and slabs," Construction and Building Materials, vol. 20, no. 1-2, pp. 59-70, 2006.

[6] ISIS Canada, "Strengthening Reinforced Concrete structures with externally-bonded fibre reinforced polymers," Design Manual 4, ISIS Canada, 2001.

[7] American Concrete Linstitute, "Guide for the design and construction of externally bonded FRP systems for strengthening concrete structures," ACI Committee 440-F Draft Document, 2000.

[8] S. K. Yoon, A study on the fatigue behavior and the fatigue design of the reinforced concrete deck slabs of the composite bridges [Ph.D. dissertation], Seoul National University, 1996.

[9] Korea's Ministry of Construction and Transportation, Annual Statistics Report of Road Traffic Density, 2000.

[10] P. C. Perdikaris, S. R. Beim, and S. N. Bousias, "Slab continuity effect on ultimate and fatigue strength of reinforced concrete bridge deck models," ACI Structural Journal, vol. 86, no. 4, pp. 483-491, 1989.

[11] Y. Maeda and S. Matsui, "Load-carrying capacity and remaining life of first-built composite Girder Bridge in Japan," in Proceedings of the Composite and Mixed Construction, pp. 50-59, 1985.

[12] J. R. Yost and E. R. Schmeckpeper, "Strength and serviceability of FRP grid reinforced bridge decks," Journal of Bridge Engineering, vol. 6, no. 6, pp. 605-612, 2001.

[13] H. Li, T. Yi, M. Gu, and L. Huo, "Evaluation of earthquakeinduced structural damages by wavelet transform," Progress in Natural Science, vol. 19, no. 4, pp. 461-470, 2009.

[14] J. Sim and H. Oh, "Structural behavior of strengthened bridge deck specimens under fatigue loading," Engineering Structures, vol. 26, no. 14, pp. 2219-2230, 2004.

[15] B. H. Oh, "Fatigue-life distributions of concrete for various stress levels," ACI Materials Journal, vol. 88, no. 2, pp. 122-128, 1991.

[16] J. A. Collins, Fatigue of Materials in Mechanical Design, John Wiley \& Sons, New York, NY, USA, 1981.

[17] H. Oh, J. Sim, and C. Meyer, "Fatigue life of damaged bridge deck panels strengthened with carbon fiber sheets," ACI Structural Journal, vol. 102, no. 1, pp. 85-92, 2005.

[18] P. C. Perdikaris and S. R. Beim, "RC bridge decks under pulsating and moving load," Journal of the Structural Engineering, vol. 114, no. 3, pp. 591-607, 1988.

[19] H. S. Shang, T. H. Yi, and L. S. Yang, "Experimental study on the compressive strength of big mobility concrete with nondestructive testing method," Advances in Materials Science and Engineering, vol. 2012, Article ID 345214, 6 pages, 2012.

[20] T. H. Yi, H. N. Li, and H. M. Sun, "Multi-stage structural damage diagnosis method based on, "energy-damage" theory," Smart Structures and Systems, vol. 12, no. 3-4, pp. 345-361, 2013.

[21] H. Oh, J. Sim, and C. Meyer, "Experimental assessment of bridge deck panels strengthened with carbon fiber sheets," Composites B: Engineering, vol. 34, no. 6, pp. 527-538, 2003.

[22] C. G. Schilling and K. H. Klippstein, "Fatigue of steel beams by simulated bridge traffic," Proceedings of ASCE, vol. 103, no. 8, pp. 1561-1575, 1977.

[23] C. G. Schilling, "Stress cycle of design of steel bridge," Journal of the Structural Engineering, vol. 110, no. 6, pp. 1222-1234, 1984.

[24] American Association of State Highway and Transportation Officials, Standard Specifications for Highway Bridges, AASHTO, Washington, DC, USA, 16th edition, 1996.

[25] Korea's Ministry of Construction and Transportation, Korean Highway Design Specification, 1996. 
[26] S. W. Collins and K. R. Nowak, "Reliability of highway girder bridges," Journal of the Structural Engineering, vol. 117, no. 8, pp. 2372-2388, 1991.

[27] A. S. Nowak, A. S. Yamani, and S. W. Tabsh, "Probabilistic models for resistance of concrete bridge girders," ACI Structural Journal, vol. 91, no. 3, pp. 269-276, 1994.

[28] E. J. Gumbull, Static of Extreme, Columbia University Press, New York, NY, USA, 1958.

[29] J. P. T. Yao, "Fatigue reliability and design," ASCE Journal of the Structural Division, vol. 100, 1974.

[30] J. R. Benjamin and C. A. Cornell, Probability, Statics, and Decision for Civil Engineers, McGraw Hill, New York, NY, USA, 1970.

[31] K. C. Kapur and L. R. Lamberson, Reliability in Engineering Design, John Wiley \& Sons, New York, NY, USA, 1997. 


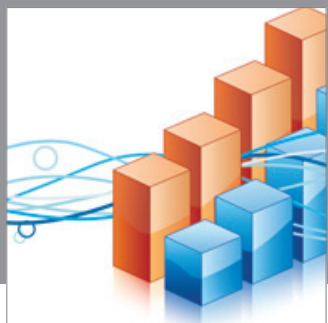

Advances in

Operations Research

mansans

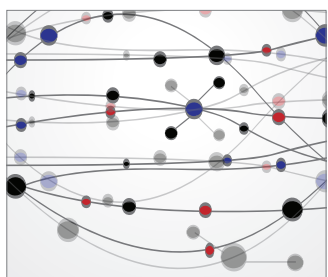

The Scientific World Journal
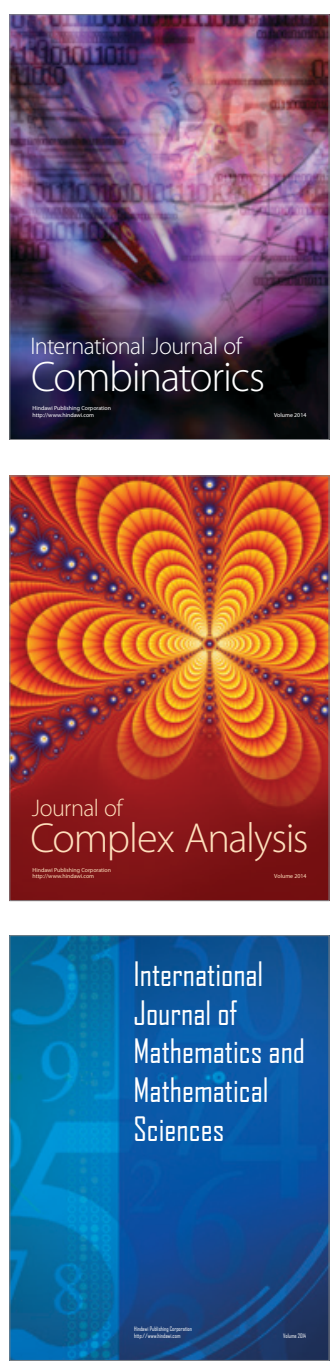
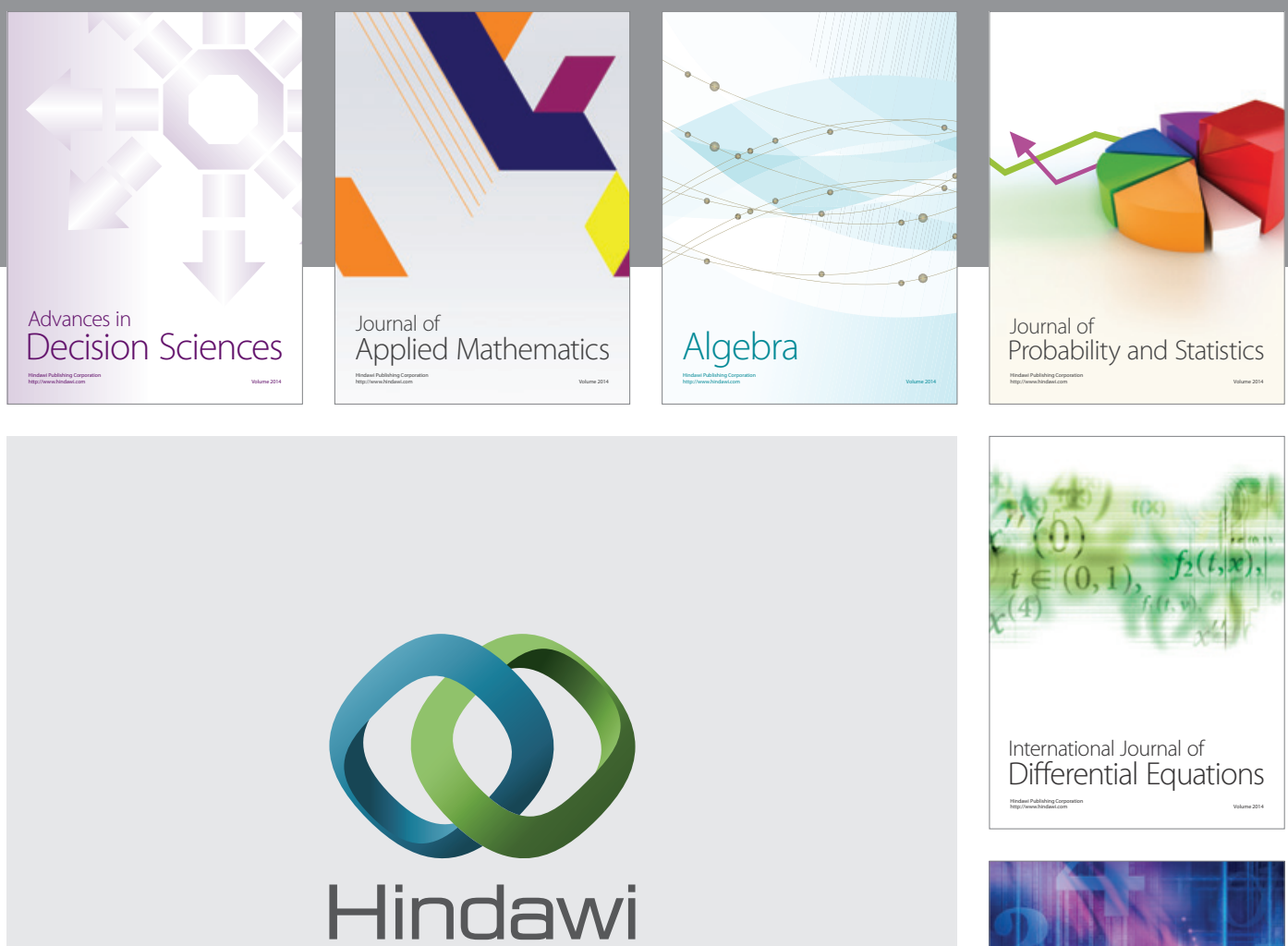

Submit your manuscripts at http://www.hindawi.com
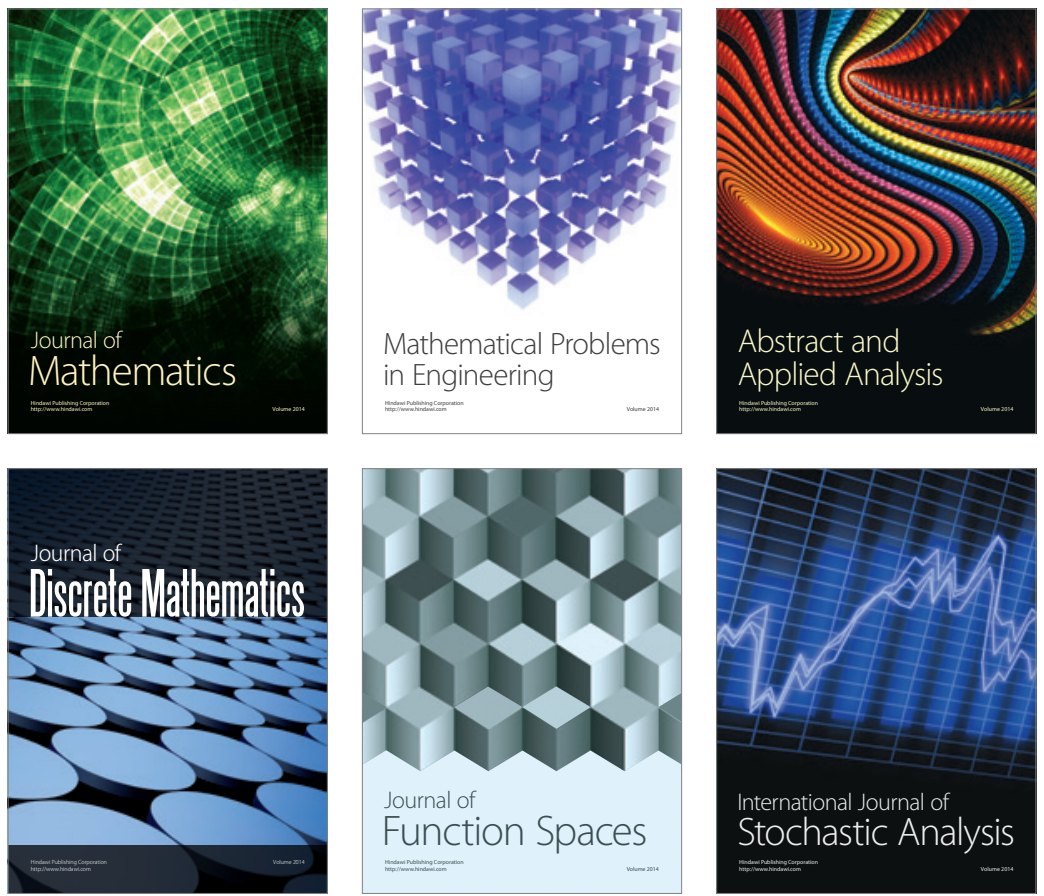

Journal of

Function Spaces

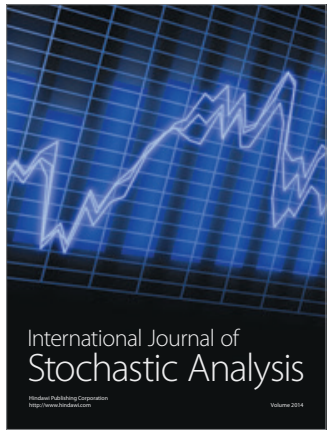

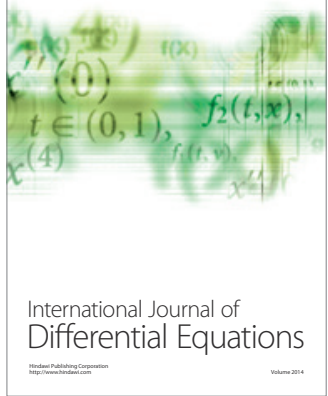
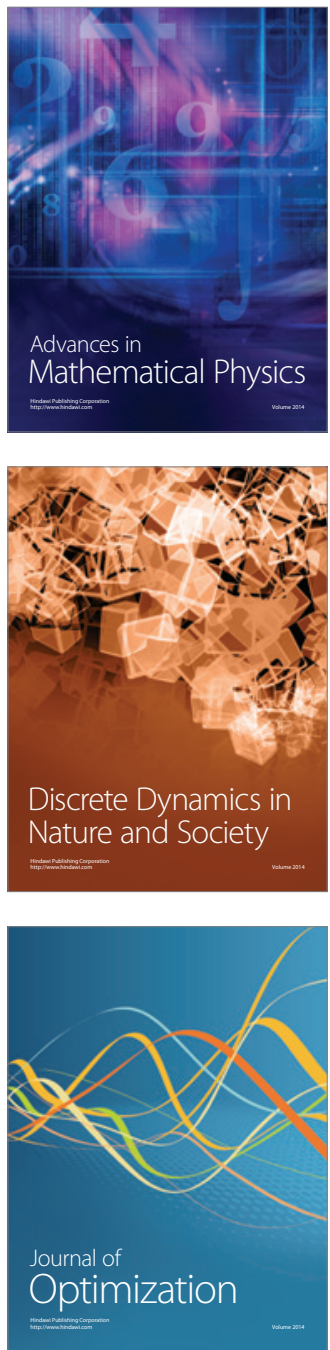